ENSAYOS

\title{
Cuerpos inmigrantes, cuerpos ideales. El racismo y la educación en la construcción de la identidad*
}

\author{
Immigrant bodies, ideal body. \\ Racism and education in the construction of identity
}

\author{
María Emilia Tijoux ${ }^{a}$, Juan Riveros Barrios ${ }^{a}$ \\ ${ }^{a}$ Universidad de Chile. \\ emiliatijoux@uchile.cl, juanriveros14@gmail.com
}

\begin{abstract}
RESUMEN
El presente artículo busca entregar elementos para la reflexión sobre el cuerpo migrante visto a contracorriente del cuerpo ideal. Tomando en consideración las políticas estatales de identificación de la población, como así también el creciente individualismo, el cuerpo se ubica en un lugar significativo en la construcción de identidades. El cuerpo como producto de la socialización se transforma en objeto de cuidado, de culto dietético, de belleza y de prácticas que lo identifican a una identidad y a un lugar determinado dentro de las lógicas de orden. Pero también es objeto de rechazo y puede convertirse rápidamente en estigma cuando no cumple con el «canon ideal» o no se adecua a las «formas culturales» imperantes. A falta de políticas de educación sobre la diversidad cultural, lo que prolifera son más bien los prejuicios desde la «diferencia» permanente frente a un otro «extraño». Es lo que suele ocurrir con los inmigrantes, y los hijos de estos en el contexto escolar, visibles no solo por su denominación de «inmigrantes» sino además por su cuerpo en tanto es signo y marca de una discriminación racial.
\end{abstract}

Palabras claves: discriminación, diferencia, violencia.

\begin{abstract}
This article aims to provide elements for reflection on the migrant body seen against the current of the ideal body. Taking into consideration the state policies of identification of the population, as well as the growing individualism, the body is located in a significant place in the construction of identities. The body as a product of socialization is transformed into an object of care, of dietetic cult, of beauty and of practices that identify it to an identity and a specific place within the logics of order. But this too is the object of rejection and can quickly become a stigma when it does not comply with the «ideal canon» or does not conform to the prevailing «cultural forms». In the absence of education politics on cultural diversity, what proliferates are rather the prejudices from the permanent «difference» to the other «stranger». This is what usually happens with immigrants, and their children in the school context, visible not only because of their denomination of «immigrants» but also because of their body as a sign and mark of racial discrimination.
\end{abstract}

Key words: discrimination, difference, violence.

\footnotetext{
* El presente artículo se inserta en las reflexiones preliminares llevadas a cabo en el Proyecto PIA Conicyt SOC180008 de Anillos de la Universidad de Chile: "Contemporary Migrations in Chile: Challenges to Democracy, Global Citizenship, and Access to Non-discriminatory Rights"; y que atañe a las consecuencias que tiene el proceso de racialización en los y las inmigrantes en Chile.
} 


\section{INTRODUCCIÓN}

El cuerpo como producto de la socialización, mantiene un lugar significativo en la construcción de identidades. Si la superficie del cuerpo es evaluada y moldeada socialmente, es debido a la fuerza que tiene un discurso «universalista», como lo es el pensamiento sobre el cuerpo basado en la conformidad de las «normas sociales». Para tener una idea de los alcances de esta «universalidad», podríamos decir, siguiendo a Balibar, que el «universalismo de la ideología dominante está arraigado a un nivel mucho más profundo que la expansión mundial del capital» (Balibar y Wallerstein, 1991, p. 16). Esto es así cuando observamos que el fenómeno «globalizante» de las redes de comunicación también adquieren un rasgo decisivo en esta «universalidad». Efectivamente, con las redes sociales estas ideas particulares no se debilitan, como podríamos suponer, sino más bien se hacen «universales» a través del «fortalecimiento y de la imposición violenta de voluntades particulares» (Geulen, 2010, p. 11). Con la globalización, observamos cada vez más «nuevos fenómenos de afirmación nacional o de peculiaridad cultural» (p. 11) que defienden constantemente una identidad con respecto a cualquier diferencia frente a un otro. Al final del día, será esta «universalidad» la que terminará definiendo lo «normal» y lo «anormal», como así también la diferenciación y la separación de determinados miembros de una sociedad que no se adecuen a este sistema de jerarquías.

Esta evaluación social, como observaremos, alude principalmente a un proceso de valorización de los cuerpos dependiendo de la importancia de su origen, de una clase específica, del género o de la «raza», este cálculo suele detenerse principalmente en determinados rasgos fenotípicos o el color de piel. El cuerpo advierte de los juicios construidos sobre los criterios morales que conforman a la sociedad y por ello es importante abordarlo desde hechos específicos, como aquellos que suelen interrumpir las rutinas cotidianas, por ejemplo, en el contexto educacional donde los niños inmigrantes se enfrentan al fenómeno del racismo. Si pensamos al cuerpo desde el fenómeno migratorio que experimenta Chile, vemos que la realidad nos muestra juicios sobre los inmigrantes teñidos por un racismo que no es nuevo. Es interesante, en este punto, la reflexión de Adam Przeworski sobre si el racismo es algo nuevo o si es algo que siempre estuvo allí. Al respecto el autor nos dirá:

Las principales cuestiones respecto de la ideología, de la cultura y de las variadas actitudes y posturas reveladas por las encuestas es si acaso cambiaron con el tiempo como resultado de otras transformaciones sociales, o si acaso estuvieron siempre allí y simplemente se hicieron públicas porque ahora hay políticos no ortodoxos que las autorizan. La xenofobia, el racismo, el nativismo, la intolerancia y otros prejuicios, ¿son algo nuevo, o simplemente se las reprimió temporalmente mediante la hipocresía, que de repente perdió su «fuerza civilizatoria»? (Przeworski, 2017, p. 28).

Si el racismo no es algo nuevo, es porque lo que se nos presenta como tensión o polaridad en la sociedad entre dos «razas», es más bien la reaparición de su propio pasado (Foucault, 2001). Para Foucault será esta infiltración lo que se nos devela como «el reverso y el fondo de la raza que aparece en ella» (Foucault, 2001, p. 65). Esto ocurre porque la «diferencia», que se experimenta con ese otro «extraño», se ha construido de manera permanente a partir del marcador «raza», es esta «naturalización» de la diferencia la que sigue permaneciendo 
como idea. Aun cuando esta construcción no es inherente al ser humano pues es un aparato discursivo - ficcional_, esta aun opera como una fuerza que consigue poner en escena al cuerpo para funcionar política y económicamente ante la presencia de inmigrantes. De aquí que el discurso es defender la sociedad de los peligros de la otra «raza». Es allí donde surge un racismo de Estado, «un racismo que una sociedad va a ejercer sobre sí misma, sobre sus propios elementos, sobre sus propios productos; un racismo interno, el de la purificación permanente, que será una de las dimensiones fundamentales de la normalización social» (Foucault, 2001, p. 66).

Es esto lo que hace visible aquello oculto a través de un proceso de racialización que opera globalmente en la producción y reproducción de la diferencia racial, también lo vemos en la estratificación social e individualmente en las subjetividades. El carácter social de la «raza», consigue que las categorías raciales se transformen en el tiempo y regresen, para «explicar» características personales, intelectuales o morales que tiene una persona. Estos hechos provienen, siguiendo a Goffman (2006), de la forma tribal del estigma, reconocido en comportamientos de descalificación cultural que visibilizan al inmigrante por su color y sus rasgos gracias a la fuerza de la «raza», cuestión que nos invita a considerar al cuerpo como lugar teórico y metodológico para el análisis de las interacciones más cotidianas.

\section{EL CUERPO, LA «RAZA»Y LA CLASE}

El racismo científico reconocía la existencia de «razas», clasificaba a los seres humanos en superiores e inferiores y establecía categorizaciones para su «ordenamiento». Actualmente, la violencia observable contra los inmigrantes moviliza esta idea clasificatoria y de «orden» ${ }^{1}$ a partir de la «raza», lo que conduce a preguntarse sobre su construcción, estructuración y subjetivación. Así podemos afirmar que la «raza» es fuente de un racismo moderno que proviene de dos raíces globalmente afines: la constitución de los Estados-naciones y la expansión colonial europea (Balibar y Wallerstein, 1991).

Lo mismo ocurre con la noción de clase. Este concepto nos muestra que el cuerpo es la fuente de un dinamismo particular, el lugar «donde se anudan la intersubjetividad práctica y la constitución de la experiencia» (Haber y Renault, 2007, p. 19). De modo que es el propio cuerpo el que sufre la violencia de la explotación por la apropiación capitalista de las fuerzas corporales, es esta expoliación la que produce efectos alienantes y reificantes en la constitución de un cuerpo socialmente determinado por las relaciones de clases y también de género. El valor que representa la fuerza de trabajo va mucho más lejos que el cuerpo donde se imprime, ya que siguiendo a Marx (2009) podemos entender que la fuerza de trabajo, o la potencia del trabajo, es el resumen de todas aquellas capacidades físicas e intelectuales que existen en la corporeidad, es decir en la personalidad viva de un ser humano que éste pone en movimiento cada vez que produce valores de uso de alguna especie. Por esto, para Marx, el cuerpo es más que un cuerpo fisiológico, es un conjunto de relaciones de dominación específicas dado que es objeto del trabajo alienado, o sea, objeto de una producción que considera todos sus movimientos y sus creaciones cuando trabaja para otro. Claramente no es un cuerpo que le pertenezca a quien trabaja, sino que es un

Actualmente se ha escuchado hablar de «ordenar la casa» como es el caso de la nueva ley de migración nacional impulsado por el actual gobierno de Sebastián Piñera. 
cuerpo para el capitalismo. En este punto es necesario sostener que el inmigrante es fuerza de trabajo explotable y disponible. Para quien gana con él y que lo usa sabiendo que su necesidad es aún mayor que la de cualquier otro trabajador — debido a la urgencia de envío de remesas y de manutención de sus familias-, el cuerpo no solo es objeto de producción sino además es objeto de una degradación tanto de su entorno familiar como de su persona. Es de este modo como se cierra el círculo de su cosificación, el inmigrante en tanto objeto y rechazo a la vez, es permanentemente humillado y amenazado de su expulsión inminente.

Plantear al cuerpo de este modo, desde la «raza» y la clase, y entendiendo a la nación como lugar fundamental de su construcción — donde se dan cita la historia, la economía y la política一, rompemos con la experiencia ontológica-individualista que lo considera como expresión natural de la persona. El cuerpo, como hemos dicho, es producto de la socialización, es el lugar de la representación y reproducción de los individuos, como también de sus identidades sexuadas y sociales. La hexis corporal, un conjunto de disposiciones prácticas corporales que alude a la manera de caminar, sostener y mantener el cuerpo, al modo de hablar, saludar, etc., permite ingresar en la lógica del habitus, es decir, a unos «sistemas de disposiciones duraderas y transferibles» (Bourdieu, 2007, p. 86) como son las maneras de sentir, de pensar y actuar. El cuerpo, por tanto, es soporte del aprendizaje, el lugar del adiestramiento, de los cuidados y del sostenimiento que refieren a la incorporación estructural de diversas jerarquías. Pero es necesario declarar que es la acción cotidiana la que se revela sobre el cuerpo en cada gesto y movimiento, aun por muy pequeño y simple que sea, para dar cuenta de un orden del cuerpo, es decir, de una jerarquización social y una moral específica.

Pero las exigencias de la vida actual obligan al individuo a buscar al cuerpo para existir, a presentarlo cada vez al mundo y a sus múltiples exigencias, a rejuvenecerlo, adelgazarlo, vestirlo «bien», a combinarlo e imitarlo. Así el sujeto es obligando a una búsqueda de perfección para parecerle bien a quienes lo juzgan, o lo pueden juzgar, según modelos impuestos por las modas y por quienes la dominan cuando le atribuyen edades, medidas o colores para su aceptación. Frente a esa presión, el individuo busca igualarse con la moda o «subir» hacia una clase y diferenciarse de otra. Para Simmel, las modas son siempre modas de clases. Las capas superiores buscan con ellas distinguirse de las inferiores para abandonarlas cuando las capas inferiores tratan de apropiárselas. De ahí que el autor diga que la moda es una forma de vida tan particular como otras, que tiende a igualarse socialmente y a distinguirse individualmente (Simmel, 1957), para unir y separar: unir con quienes el individuo desea socializar y separar de otros con aquellos con los que no quiere confundirse.

\section{MODA SACRIFICIAL Y CUERPO MIGRANTE}

Para Le Breton el cuerpo se adapta a las circunstancias, como una suerte de materia prima modelable que satisface la vida social y que permite «entrar en la moda» $\mathrm{O}$ «estar a la moda». Es un referente fundamental en constante cambio, que le obliga a seguir este modo de vida, por eso es probable que, en esa compleja y sufriente búsqueda, el individuo se olvide de si para convertirse en alguien para otro, en alguien que busca siempre distinguirse, pero sin una subjetividad propia. Es esta constante desubjetivación del individuo, la que termina por alienarlo en la vorágine del consumo y de su consumo. Así, la identidad quedaría expuesta 
a los cambios al igual que el cuerpo, pues para seguir las exigencias deberá cortarse, estirarse, modelarse, ingerir medicamentos, privarse de comida, operarse. ¿Será entonces el cuerpo un puro accesorio separado de quien lo porta? Quizás este es un nuevo dualismo laico, como bien lo advierte Le Breton (2007), donde el cuerpo termina siendo la antítesis del hombre.

Del otro lado de esta moda sacrificial está el cuerpo inmigrante, señalado constantemente por el racismo. Es este racismo el que remite a rasgos de «pureza» y de «superioridad», es decir a una jerarquía cultural y racial constatada en afirmaciones del sentido común sobre «razas puras» o «culturas diferentes» plantadas en el nosotros desde voces que dicen: «no somos como ellos(as)». Una enunciación que debería conducirnos a preguntarnos por lo que eso significa, por cómo se construye el nosotros y por el lugar que tenemos y que sentimos frente a un inmigrante. El racismo es una potente ideología que puede abordarse desde la lógica universalista y la falsa conciencia que justifica y legitima la dominación, cuando la diferencia hecha «raza» se convierte en su pivote. Esta se basa en la creencia de una «diferencia natural», un postulado que infiere que es la propia naturaleza la determina los rasgos culturales (Guillaumin, 1973) porque la función que cumple la «raza» es hacer creer que las diferencias están inscritas en la naturaleza y que son inalterables. De ahí que la primera operación del racismo sea observar - o inventar - un comportamiento o un rasgo particular de una persona o de un grupo, para luego asimilarlo a una «pertenencia» y después generalizarla recurriendo a argumentos biológicos.

Hoy el racismo se observa en distintas dimensiones, tal como aquella que advierte sobre el surgimiento de la violencia en distintos países cuando los Estados reaccionan contra los desplazamientos de una fuerza de trabajo precarizada y protagonizada por trabajadores inmigrantes. Así se van instalando las «diferencias» que histórica y políticamente se han construido sobre atributos esencializados que devienen en una suerte de segunda naturaleza (De Rudder, Poiret y Vourc'h, 2010) de la cual debemos ser conscientes de sus peligros. ¿Es posible superar esta diferenciación que hacemos permanente frente a un otro? ¿Cómo educar a nuestros niños de esta continua naturalización que exacerba la diferencia? Tevanian (2017) nos señala que el racismo es una mecánica cuyo carácter artificial naturaliza el miedo a un otro supuestamente desconocido (cuando el racista si conoce y reconoce a quien odia). Plantear al racismo como una mecánica artificial, la cual podemos controlar, pero no eliminar, nos mantiene precavidos de aquella falsa explicación que naturaliza el miedo a la vez que exime y banaliza la violencia que contiene esa naturalización. En contraste con este enfoque artificial o «naturalista» del miedo hacia lo desconocido, es posible empezar a educar a partir de las dimensiones culturales, históricas, económicas y sociales propias de los individuos. Efectivamente, para Rancière (1996), es posible encontrar todo tipo de razones económicas y sociológicas para este «nuevo» racismo, de modo que lo que urge es repensar y educar desde la singularidad de la política las nuevas formas de interacción y de sociabilidad en común, construir nuevos lugares de lo político, espacios de subjetivación entre un yo y un otro.

El «nuevo» racismo es el odio del otro que ocupa el terreno cuando la polémica política se borra. La cultura política del conflicto puede haber provocado consecuencias decepcionantes. Pero también ha sido un medio para regular lo que se mantiene por fuera de la política: la identificación de la figura del otro con el objeto de odio. La pasión identitaria es asunto de miedo: el miedo indeterminado que encuentra en el 
cuerpo del otro su objeto. La puesta en escena política, heterológica del otro, ha sido también un medio de civilizar este miedo. Los resurgimientos presentes del racismo y de la xenofobia significan entonces un desmoronamiento de la política, el retorno del tratamiento político del daño al odio primordial. El problema entonces no es simplemente enfrentar un «problema político». Es reinventar la política (Rancière, 2006, p. 25-26).

Estas «nuevas» formas de racismo, unidas a desmoronamiento de la heterología política, dan cuenta de una nueva figura «infra-política». A falta de subjetivación política y de un nombre identitario, la figura de otro se transforma en puro objeto de odio y rechazo (Rancière, 2006).

El inmigrante de hoy es en primer lugar un obrero que perdió su segundo nombre, que perdió la forma política de su identidad y su alteridad, la forma de una subjetivación política de la cuenta de los incontados. No le queda, entonces, más que una identidad sociológica, que bascula a la sazón en la desnudez antropológica de una raza y una piel diferentes (Rancière, 1996, p. 148).

Si nos detenemos en las dimensiones sociales, aquellas que el racismo expresa a través del odio y el miedo indeterminado, podemos constatar sus diferentes dimensiones. Podemos citar, por ejemplo, a una profesora que señalaba lo siguiente: «los reconozco por su olor, por como huelen estos niños, porque comen distinto y eso los hace tener ese olor»; o una médica que decía: «es su cuerpo, es su forma rara, tan distinta a como somos nosotros»; o según otra entrevistada: «sabemos que son peligrosos»- ¿Cómo lo sabe? - «lo sé, lo sé cuando los veo». Porque parece que basta con mirar. Mirar su cuerpo. Ese cuerpo que el «ve». Estas calificaciones que parten de la condición de inmigrante, del origen, el color, la labor que desempeñan, vienen a explicar un modo de ser y a señalar ese racismo que vuelve a definir características culturales o psicológicas. Un chofer de taxi, al pasar por el centro de la ciudad de Santiago en calle Catedral (donde desde los años noventa los inmigrantes se reúnen) se ríe y dice que estamos en Lima «porque está lleno» - ¿de quién?- «De ellos pues» - ¿y quiénes son ellos?- «Todos, todos los que han llegado y por eso hay que tener cuidado, porque son así» -¿de qué hay que tener cuidado?- «de todo», repite varias veces sin aludir a nada. Pero cuando advierte que «son así» parecer referir con total seguridad al hecho de que son contrarios, distintos, probablemente «inferiores» a lo que él es, como si fuesen un «todo», una universalidad que advierte de posibles formas de peligro de las cuales hay que cuidarse. ${ }^{2}$ El problema no es evitar esa «universalidad» totalizante y escindida entre un yo y otro, el problema para Rancière es dónde situamos el momento de lo universal. Una clave sería reconocer la diversidad a través del principio de la igualdad, esto significa educar desde la singularidad de esos universos subjetivos y comunes. Situar el momento de lo universal significa pensar lo universal ya no en el plano de una naturalización de las diferencias sino más bien de reflexionar lo universal desde la igualdad de naturaleza. La tarea es potenciar una pedagogía igualitaria que refuerce las historias en común, una pedagogía que devele esos universos discursivos igualitarios y demuestre que un sujeto va más allá de una supuesta «raza» o clase social. En definitiva, educar desde el mundo de

Entrevistas, años 2008, 2014 y 2018. 
las palabras donde se recrean las historias y los tiempos a partir de un universo sensible de cada subjetividad. Esto sin duda supone oponer, en contra del tiempo homogéneo de los aparatos gubernamentales y la relación jerárquica entre lo universal y lo particular, el tiempo heterogéneo de la igualdad. El tiempo que abre la posibilidad de relacionarnos con los otros y entendernos a nosotros mismos.

En trabajos de comienzo de este siglo, Tevanian señalaba que el inmigrante era un cuerpo de excepción que puede ser considerado visible o invisible. Visible para ser atacado o mal mirado, también «sentido» o para ser rechazado, violado o castigado; invisible para ser abandonado, botado en la frontera, dejado en las escaleras de un hospital, ignorado. Es una producción de excepción que remite a una discriminación racista que no tiene que ver con la diferencia, entendida como tal, sino con la construcción jurídica, con políticas públicas de excepción, como un cuerpo sometido en todo lugar y en todo tiempo a un estado de excepción (Tevanian, 2005).

El inmigrante trae consigo un cuerpo sentido como invasivo, peligroso, productor de enfermedades diversas. Poco importa que se demuestre lo contrario, porque su figura inmigrante construida como diferencia del chileno y de otros extranjeros evaluados como no-inmigrantes, es decir como personas que pueden permanecer o ser bienvenidos en Chile, es una figura que será siempre juzgada por lo que haga o no haga, independientemente de la verdad que dicha presencia entregue para ser probada. Su inmigración colocada en el cuerpo, es decir su ser inmigrante ya está incorporado negativamente en el habitus chileno: «estos colapsan los servicios públicos»; «les roban el trabajo a los chilenos», «llenan los cupos de los jardines infantiles», «llenan las escuelas», etc., quiere decir que estarían invadiendo el espacio público nacional-chileno. Su cuerpo incomoda, molesta, complica y por eso es mirado, juzgado, examinado en todo lo que hace o es. Se juzga su habla, tanto por considerarse incomprensible o por hablar el español con un acento que no gusta, también su forma, su altura o su talla. Molesta su color mientras más oscuro sea y sus rasgos cuando remiten a una historia que se busca borrar. Complica su música y se critican sus fiestas.

Por otra parte, la producción de discursos con respecto a los inmigrantes es variada y las redes sociales sirven de plataforma para que algunos puedan proferir discursos de odio cargados de violencia. La amenaza que a priori el inmigrante supone lo va dejando fuera de la posibilidad de alguna igualdad que lo dignifique, provocándole un sufrimiento social que debería ser considerado más temprano que tarde en un país que desde los años 90 es un país de inmigración.

\section{CONCLUSIONES}

El racismo cotidiano, aquel que asistimos actualmente es un racismo totalmente eufemizado, inscripto en el habitus común. Este, como podemos suponer, se encuentra lleno de sutilezas, conversaciones al pasar, dichos de pasillos, etc. Pero este fenómeno, como hemos dicho, no es algo «nuevo», no es algo que sea característico de la «época» o del pensamiento de algunos políticos racistas y xenófobos, más bien es parte de nuestra propia racionalidad histórica, de un pensamiento que exacerba lo propio y que se opone a toda identidad que manifieste una diferencia con su centro. El llamado retorno de este fenómeno, aquel que hacía alusión Foucault (2001), es la reaparición de su propio pasado, la reaparición del 
peligro que aparece desde su propio cuerpo, el enemigo interno. Es así que el racismo es generado por la propia sociedad. La «pasión identitaria» que vemos manifestarse por doquier en nuestros países, tiene estrecha relación con el retorno de una «racionalidad» del Estado, y es dicha «racionalidad» la que terminará produciendo el racismo (Rancière, 2010).

La nueva ley de migración se propone no solo «ordenar» a partir de la «casa» —pues instala en primer lugar de la argumentación el «orden»—, también se procura cuidar las formas de integración y de exclusión, también podemos suponer con ello que se hace una obra de justicia y de paz social (Rancière, 1996). Pero esta obra debe hacer que «lo particular entre en la esfera de su universalidad. Al separar a los buenos extranjeros de los indeseables, se supone que desarma el racismo que se nutre de la amalgama» (Rancière, 1996, p. 150). Sin duda algo muy conocido, pero también algo muy pensado en la nueva ley de Migraciones impulsada por las actuales autoridades. El hecho es que el inmigrante que vemos a diario, aquel que ha quedado fuera de toda igualdad y dignidad, es el que ha perdido su alteridad que lo unía a una subjetivación política — a una identidad común que lo dignificaba (pueblo, obrero, proletario, etc.). El llamado «problema» de la inmigración que reemplaza a un fenómeno social que debiera ser entendido como tal, es entonces más precisamente un problema de identidad, una cuestión política de reparto de lo común, una partición de lo sensible (Rancière, 1996). A falta de identidad que lo fije a una comunidad de los iguales el «problema» del racismo se transforma rápidamente en un odio por la condición infra-política del inmigrante. Será esta falta de identidad la que termina por fomentar todos los discursos de rechazo contra una alteridad que no posee su forma política. Tal vez ahora podamos comenzar a ver el real alcance de este fenómeno del racismo, sus dimensiones en la cotidianeidad, sus miedos y su violencia.

Hemos querido desde el cuerpo pensar al individuo mujer u hombre, como así también a las niñas y niños inmigrantes que habitan hoy en Chile. Sin duda ya hay muchos que se han insertado en la vida chilena y forman, de cierto modo y con muchas exigencias, parte de esta nación que aún tiene mucho que decir y escribir sobre el modo en que se les ha tratado, tanto a los inmigrantes que atraviesan nuestras fronteras como a quienes migraron hacia distintas regiones intentado una mejor vida. Sin embargo, la realidad nos sigue sorprendiendo en su violencia. ¿Cómo actuar frente al discurso racista, más aún si este se encuentra totalmente eufemizado? ¿Es posible dejar de relativizar esta violencia racista que vemos a diario en las calles, en el trabajo, las escuelas, las universidades? ¿Cómo educar a nuestros niños y niñas de cara a la diversidad cultural? Si las políticas de gobierno convergen en garantizar a los inmigrantes el derecho a la educación y a la inclusión en el sistema educacional chileno, deberíamos tener además una política educacional pública frente al racismo que respete y fomente la diversidad cultural tanto de las comunidades de inmigrantes como de nuestros pueblos originarios. El documento sobre «Recomendaciones de políticas públicas contra el racismo en Chile» del Departamento de Sociología de la Universidad de Chile, ya es un paso en ese sentido al proponer una hoja de ruta frente a estos problemas que nos aquejan como sociedad.

Deberíamos estremecernos ante las voces de niños y de niñas que nos dicen que todos los días, en el contexto educacional, otros niños les castigan por su color de piel y más aún cuando explican con voz calma que ya se han ido acostumbrando, que prefieren evitan los problemas juntándose entre ellos, que regresan generalmente juntos a sus casas para defenderse, que no quieren pelear porque los pueden expulsar de la escuela. También cuentan que callan las situaciones de violencia cotidiana ante sus padres para no 
complicarles más la vida. Resulta violento ver que a unos pasos donde nos encontramos trabajando, en una pequeña plaza de juegos de una población ${ }^{3}$, un grupo de niños de esa población los expulsen diciéndoles que no juegan con negros y que deben irse de allí. La excepción ha sido enseñada por los adultos, aprendida por los niños y difundida por un sentido común afincado en los cuerpos que se busca aniquilar o ignorar.

\section{REFERENCIAS BIBLIOGRÁFICAS}

Balibar, É. y Wallerstein, I. (1991). Raza, nación y clase. Madrid: IEPALA.

Bourdieu, P. (2007). El sentido práctico. Buenos Aires: Siglo XXI Editores.

De Rudder, V. Poiret, C. Vourc'h, F. (Eds) (2010). L'inégalité raciste: l'universalité républicaine à l'épreuve. Paris: PUF.

Foucault, M. (2001). Defender la sociedad. Curso en el Collège de France (1975-1976). Buenos Aires: Fondo de Cultura Económica.

Geulen, C. (2010). Breve historia del racismo. Madrid: Alianza Editorial.

Guillaumin, C. (1973). L'Idéologie raciste: genèse et langage actuel. La Haya: Mouton.

Goffman, E. (2006). Estigma. La identidad deteriorada. Buenos Aires: Amorrortu.

Haber, S. y Renault, E. (2007). Une analyse marxiste du corps? En Corps dominés, corps en rupture. Revista Actuel Marx, (41), Paris: PUF.

Le Breton, D. (2007). Adiós al cuerpo. México: La Cifra Editorial.

Marx, K. (2009). El capital, Libro I (trad. P. Scaron). México: Siglo XXI.

Przeworski, A. (2017). ¿Qué está pasando? En Democracia y representación, Revista Actuel Marx/ Intervenciones, (23), (pp. 13-47), Santiago: Lom.

Rancière, J. (1996). El desacuerdo. Política y filosofía. Buenos Aires: Nueva Visión. . (2006). Política, policía, democracia. Santiago: Lom.

. (2010). El racismo. Una pasión que viene de arriba. En Revista El Viejo Topo, (275), (pp.

55-57). Barcelona: Ediciones de Intervención Cultural.

Simmel, G. (1957). Fashion. En The American Journal of Sociology, 62(6), 541-558.

Tevanian, P. (2017). La mécanique raciste. Paris: La Découverte. . (2005). Le corps d'exception et ses métamorphoses. Réflexions sur la discrimination raciste.

Disponible en: http://lmsi.net/Le-corps-d-exception-et-ses-mA-c.

Escuela de Temporada en Iquique, UNAP y U. de Chile, enero, 2019. 
